\title{
Wave Climate from Spectra and Its Connections with Local and Remote Wind Climate
}

\author{
HAOYU JIANG \\ College of Marine Science and Technology, China University of Geosciences, Wuhan, and Laboratory for \\ Regional Oceanography and Numerical Modeling, Qingdao National Laboratory for Marine Science and Technology, \\ Qingdao, and Shenzhen Research Institute, China University of Geosciences, Shenzhen, China \\ LIN MU \\ College of Marine Science and Technology, China University of Geosciences, Wuhan, and Shenzhen Research Institute, \\ China University of Geosciences, Shenzhen, China
}

(Manuscript received 20 July 2018, in final form 17 December 2018)

\begin{abstract}
Wind-generated waves can propagate over large distances. Therefore, wave spectra from a fixed point can record information about air-sea interactions in distant areas. In this study, the spectral wave climate for a point in the tropical eastern Pacific Ocean is computed. Several well-defined wave climate systems are observed in the mean wave spectrum. Significant seasonal cycling, long-term trends, and correlations with the Southern Oscillation, the Arctic Oscillation, and the Antarctic Oscillation are observed in the local wave spectra, showing abundant climatic information. Projections of wind vectors on the directions pointing to the target location are used to connect the spectral wave climate and basin-scale wind climate, because significant correlations are observed between the wave spectra and the wind projections of both local and remote wind systems. The origins of all the identified wave climate systems, including the westerlies and the trade winds in both hemispheres, are clearly shown in wind projection maps. Some of these origins are thousands of kilometers away from the target point, demonstrating the validity of this connection. Comparisons are made between wave spectra and the corresponding local and remote wind fields with respect to seasonal and interannual variability and long-term trends. The results show that each frequency and direction of ocean wave spectra at a certain location can be approximately linked to the wind field for a geographical area, implying that it is feasible to reconstruct spectral wave climates from observational wind field data and monitor wind climates from observational wave spectra geographically far away.
\end{abstract}

\section{Introduction}

Wind-generated surface gravity waves (simply called waves hereafter) are a fundamental and ubiquitous phenomenon at the air-sea interface. They impact many aspects of human life, from industrial activities such as seafaring and port operations to recreational activities like surfing and yachting, and play a crucial role in many geophysical processes such as momentum exchange at the air-sea boundary layer. The studies of wave climate are important from both societal and scientific perspectives and thus are widely conducted in different scales, including global (e.g., Young 1999; Chen et al. 2002; Hemer et al. 2010, 2013; Semedo et al. 2011, 2013; Young et al. 2011, 2012; Fan et al. 2012,

Corresponding author: Lin Mu, moulin1977@hotmail.com
2013, 2014), basin (e.g., Gulev and Hasse 1998; Gulev and Grigorieva 2006; Stopa and Cheung 2014; Liu et al. 2016), regional (e.g., Weisse and Günther 2007; Anoop et al. 2015; Semedo et al. 2015), and local point scales (e.g., Bromirski et al. 2005; Gemmrich et al. 2011; Espejo et al. 2014; Portilla et al. 2015a,b, 2016).

Waves are generated by wind but are not always coupled to local winds because they can propagate away from their origins and become swells. Swells can propagate over thousands of kilometers with little energy loss (e.g., Snodgrass et al. 1966; Ardhuin et al. 2009; Jiang et al. 2016). Therefore, for a given point in the ocean, the sea state might be the superposition of a local wind-sea system and more than one swell system originated from remote regions. Analyzing waves using integral ocean wave parameters such as significant wave height (SWH), mean wave direction (MWD), and mean wave period 
(MWP) only provides a limited description of the wave field and might be misleading in a mixed sea state. Therefore, efforts have been made on the characterization of waves using spectra, such as spectral partitioning, which is an algorithm for the separation of different wave systems from different origins using a wave spectrum (e.g., Gerling 1992; Wang and Hwang 2001; Hanson and Phillips 2001; Portilla et al. 2009; Hwang et al. 2012). Wave spectral information and partitioning schemes are receiving increasing attention in both the scientific community and marine industries, as they can reveal the contributions of each wave system (e.g., Portilla et al. 2013; Portilla and Cavaleri 2016; Portilla 2018).

Waves carry the information of the wind generating them. Thus, the local wave climate derived from wave spectra can shed some information on both local and far-field wind climates (Portilla et al. 2016). However, only a few studies about the spectral wave climate have been conducted for two main reasons:

1) Buoys with the ability to measure wave spectra have not accumulated data for 30 years, which is the minimum for climate studies as recommended by the World Meteorological Organization.

2) Although methods for reconstructing wave spectra from the four Fourier coefficients measured by buoys, such as the maximum entropy method (Earle et al. 1999), are widely applied in engineering, they are also known to have problems such as reducing the directional spread and generating spurious peaks.

Bromirski et al. (2005) related the energy in different frequency bands of several North Pacific buoys with the sea level pressure (SLP) modes using principal component analysis and found some climate signals in waves. Pérez et al. (2014) presented a method for evaluating the source and travel time of the wave energy reaching any location in the open ocean using (reconstructed) global wave spectral information. Espejo et al. (2014) reconstructed a long-term spectral wave climate from long-term SLP field and relatively short-term buoy data using cluster analysis and characterized the spectral wave climate in the northeast Atlantic. Portilla et al. (2015a,b) built a systematic methodology for analyzing the local wave climate based on the spectral-domain probability density function of partitioned peak wave periods and peak wave directions, and an atlas of global spectral wave climate is developed based on this method (Portilla 2018). They showed that El Niño events have a plausible signature on the wave spectra in the eastern equatorial Pacific (Portilla et al. 2016), implying that there could be abundant climatic information in wave spectra.
The aims of this study are to establish a methodology for describing the local spectral wave climate and to provide some insights into the potential connection between local spectral wave climates and local/remote wind climates. A swell-dominated location in the tropical eastern Pacific Ocean is selected as an example to illustrate how local spectral information is correlated with the wind information thousands of kilometers away. The rest of the paper is as follows. In section 2, the data of wave spectra and sea surface wind used in this study are introduced, and some climate indices are described. Section 2 also presents the methodology for analyzing spectral wave climate and connecting it with wind information. In section 3, the spectral wave climates at the selected location are detailed with a discussion on how they are connected to local/remote wind climates. Section 4 is a summary of major findings and conclusions.

\section{Data and methodology}

\section{a. Data of wave spectra and wind field}

Contemporary numerical wave models can provide a reliable spectral description of waves, especially in the open ocean, and wave spectra from them are consistent with those measured by buoys (e.g., Stopa et al. 2016; Portilla et al. 2015b). Because of the two aforementioned problems with observational wave spectra (lacking of long-term observations and problems of spectrum reconstructing methods), numerical wave models are regarded as useful tools to investigate the wave climate (e.g., Semedo et al. 2011; Stopa and Cheung 2014; Portilla et al. 2016). This study uses a 39-yr (1979-2017) record of directional wave spectra and 10-m wind field data from the European Centre for MediumRange Weather Forecasts (ECMWF) interim reanalysis (ERA-Interim; Dee et al. 2011). ERA-Interim is a coupled atmosphere and surface wave reanalysis covering the period from 1979 to the present. The horizontal resolution of the atmospheric model is approximately $79 \mathrm{~km}$ on a reduced Gaussian grid, and the resolution of the coupled wave model is approximately $110 \mathrm{~km}$. The wave spectral information from ERA-Interim can be downloaded with a temporal-spatial resolution of $6 \mathrm{~h} \times$ $1^{\circ} \times 1^{\circ}$ using ECMWF web API. Each spectrum at a certain time and location is divided into 30 frequency bins that increase exponentially from 0.0345 to $0.5473 \mathrm{~Hz}$ and 24 directional bins with $15^{\circ}$ spacing.

The location selected in our case study is a point in the Pacific Ocean at $5^{\circ} \mathrm{N}, 120^{\circ} \mathrm{W}$ (hereafter, Point $\mathrm{X}$ ). This is a swell-dominated position with a relatively complex wave condition located in both the Pacific "swell pool" 


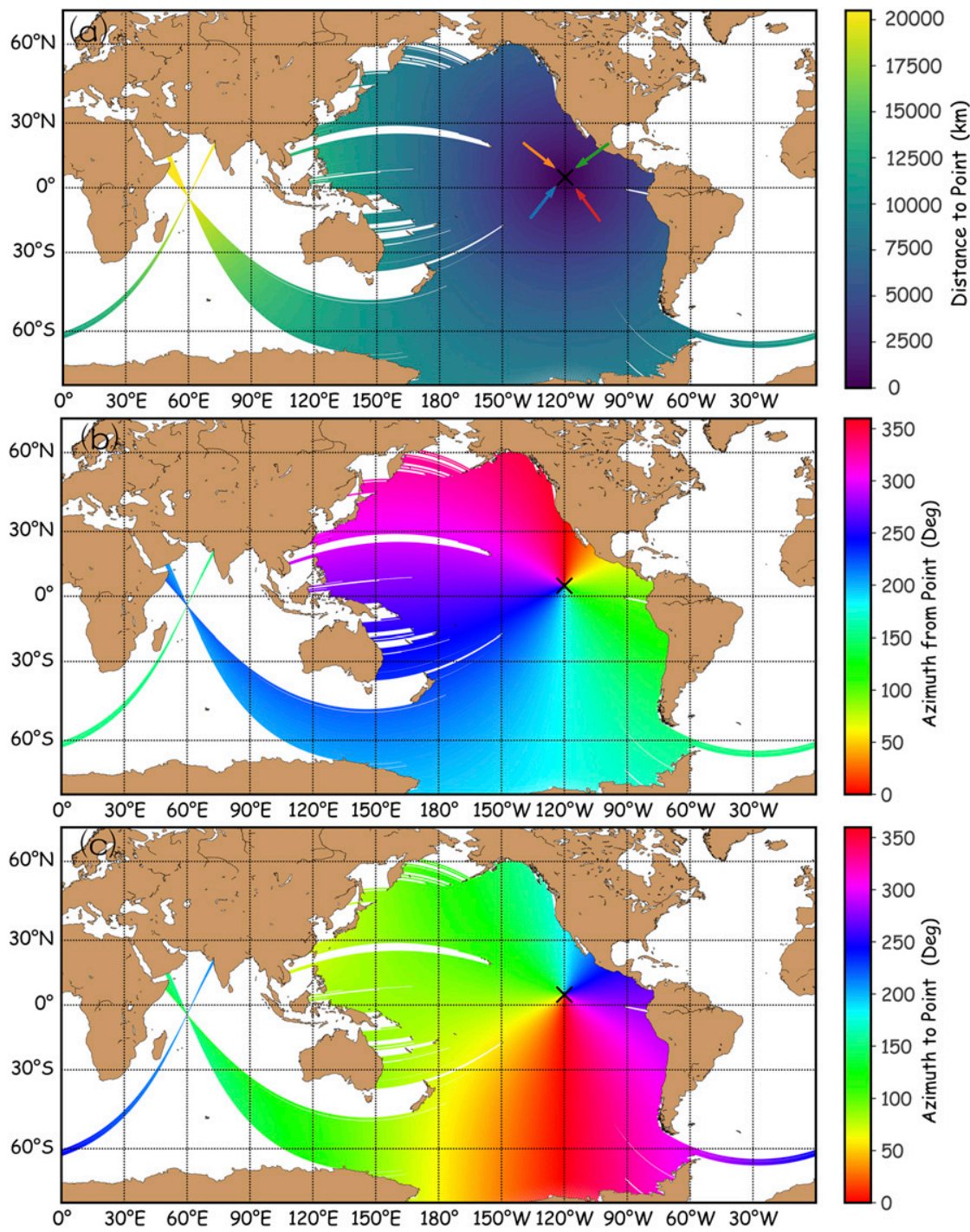

FIG. 1. Regions with potential impacts on wave conditions at the selected point (the cross) considering only the along-great-circle propagation and land blocking of waves: (a) distances from the impacting regions to the target point, (b) azimuth from the target point to different locations in the ocean, and (c) azimuth from different locations to the target point. Regarding the convention of directions, $0^{\circ}$ refers to the direction propagating to the north, and $90^{\circ}$ refers the direction propagating to the east. The four wave directions analyzed in Fig. 2 are indicated with arrows of corresponding colors in (a).

(Chen et al. 2002) and the Pacific "crossing swell pool" (Jiang et al. 2017a) where several wave systems often coexist at the same time. The swells generated by westerlies in both hemispheres can propagate into this point while it is also impacted by the intertropical convergence zone (ITCZ)-induced trade winds. The propagation of waves closely follows principles of geometrical optics, along great circles on the ocean surface, with minor deviations because of ocean currents (Snodgrass et al. 1966; Ardhuin et al. 2009). Previous studies of tracking ocean swells (e.g., Collard et al. 2009; Jiang et al. 2016, 2017b) have shown that using great circles and ignoring the effects of refraction, reflection, and diffraction can obtain good results, especially in the regions far away from the wave-generating areas. Based on this geometrical optical model, the regions where wave energy with appropriate directions can impact the selected location can be estimated by drawing great circles in different directions from the selected location, which is also demonstrated by Pérez et al. (2014). The propagating distances and the azimuth from and to the selected location are shown in Figs. 1a-c, respectively. It is noted 
that the "ocean convention" is used for the wave directions in this paper, which means that $0^{\circ}\left(90^{\circ}\right)$ refers to the northward (eastward) propagation of waves. The figures can be interpreted as the following. If wave energy at any given location propagates in the azimuth shown in Fig. 1c, this wave energy will impact the wave spectra at the selected point (the cross) after propagating over the corresponding distance in Fig. 1a, and the impacted direction in the spectra at the selected point is opposite to the corresponding directions shown in Fig. 1b. For example, it can be deduced from Fig. 1 that even waves in the tropical Indian Ocean propagating in the direction of $\sim 140^{\circ}$ might theoretically propagate into the target point, impacting the $\sim 60^{\circ}\left(240^{\circ}\right.$ minus $\left.180^{\circ}\right)$ direction of the wave spectra there, after propagating over $\sim 20000 \mathrm{~km}$. However, the frequency dispersion, the angular spreading, and the limited-but-still-significant swell dissipation will attenuate the wave energy along propagation (Jiang et al. 2017b), which makes the swell energy from small and distant regions hard to be detected. As waves are generated by wind, Fig. 1 also implies that the wave climate at a single point in the open ocean has the potential to partially reflect the remote wind climate via information contained in swells.

\section{b. Climate indices}

According to Stopa and Cheung (2014), the wind and wave climates in the Pacific Ocean are impacted by climate oscillations, including El Niño-Southern Oscillation (ENSO), the Antarctic Oscillation (AAO), and the Arctic Oscillation (AO). Many indices are developed to describe these climate oscillations. ENSO has a strong signature in the equatorial Pacific, which is usually indicated by atmospheric pressure or temperature anomalies across the Pacific basin. A frequently used index for ENSO is the Southern Oscillation index (SOI), which is defined as the difference of the SLP anomalies between Tahiti and Darwin. The AAO, also known as the southern annular mode, is defined as a low pressure surrounding Antarctica that moves north or south as its mode of variability (Gillett et al. 2006). The AO (or northern annular mode) is an oscillation equivalent to the AAO in the Northern Hemisphere (NH; Thompson and Wallace 1998). The indicators of these two oscillations are the AAO index (AAOI) and the AO index (AOI), which are both defined by the first empirical orthogonal function of geopotential height. In this study, these three climate indices are employed to identify the correlations between the local spectral wave climate and climate oscillations. Monthly SOI, AAOI, and AOI data are downloaded from the National Oceanic and Atmospheric Administration Earth System Research Laboratory (https://tinyurl.com/yd2nhcu2).

\section{c. Spectral wave climate}

The global wave energy can be described as fivedimensional (5D) wave spectral densities $G(t, \varphi, \lambda, f, \theta)$ with the given time $t$, latitude $\varphi$, longitude $\lambda$, frequency $f$, and direction $\theta$. Most studies focus on the parameters integrated along $f$ and $\theta$ such as SWH $\left(H_{m 0}\right)$, MWP $\left(T_{m-1,0}\right)$, and MWD $\left(\theta_{m}\right)$, where

$$
\begin{aligned}
& H_{m 0}=4.04 \sqrt{\iint f^{0} G(f, \theta) d f d \theta}, \\
& T_{m-1,0}=\frac{\iint f^{-1} G(f, \theta) d f d \theta}{\iint f^{0} G(f, \theta) d f d \theta}, \quad \text { and } \\
& \theta_{m}=\arctan \left[\frac{\iint \sin (\theta) G(f, \theta) d f d \theta}{\iint \cos (\theta) G(f, \theta) d f d \theta}\right] .
\end{aligned}
$$

In this case, the $5 \mathrm{D}$ array is simplified into a $3 \mathrm{D}$ temporal-spatial array $H(t, \varphi, \lambda)$, where $H$ can be any integrated parameter $\left(H_{m 0}, T_{m-1,0}\right.$, or $\left.\theta_{m}\right)$. Dataprocessing methods are developed based on this 3D array, from the simple climatological mean to classical statistical techniques such as empirical orthogonal functions. When $\varphi$ and $\lambda$ are fixed, $G(t, \varphi, \lambda, f, \theta)$ also becomes a 3D array $G(t, f, \theta)$. Each $\langle f, \theta\rangle$ (henceforth, $\langle x, y\rangle$ in the text denotes a pair of data) corresponds to a time series of spectral densities, like each $\langle\varphi, \lambda\rangle$ corresponding to a time series of SWH in $H(t, \varphi, \lambda)$. Some of these time series of spectral densities at Point $X$ are shown in Fig. 2 using 20-yr ERA-Interim wave spectra over 1981-2000 (with the data averaged monthly for clarity). Annual cycles are observed in most of the series with the energy propagating in different directions in different phases. For instance, the spectral densities propagating toward the directions of both $127.5^{\circ}$ and $232.5^{\circ}$ have the same seasonality and generally reach the maximum in boreal winter. The spectral densities in the other two directions, reaching their maximum in boreal summer, have the opposite seasonality. Some exceptionally high peaks, such as the peaks at $\langle 0.05 \mathrm{~Hz}$, $\left.127.5^{\circ}\right\rangle$ and $\left\langle 0.13 \mathrm{~Hz}, 232.5^{\circ}\right\rangle$ in the boreal winter of $1982 / 83$ and 1997/98, are well defined. They can be regarded as the signatures of ENSO and indicate that winter storms and trade winds in the $\mathrm{NH}$ are stronger during El Niño events. These features show that the information derived from local wave spectra is rich from a "climatological" point of view.

The 6-hourly wave spectra at the selected point are averaged to obtain the annual mean wave spectrum and 

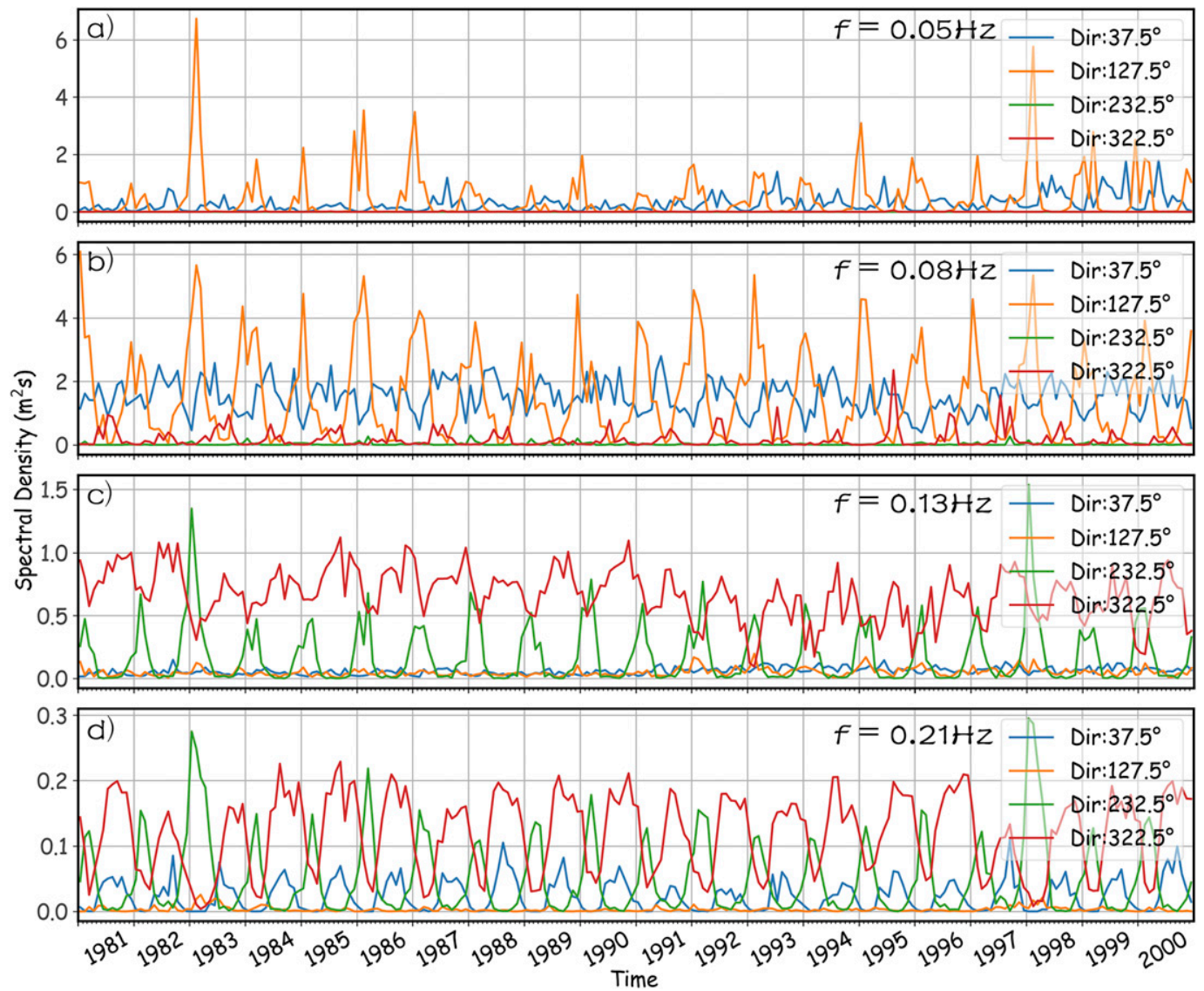

FIG. 2. Time series of monthly averaged wave spectral densities for different frequencies and directions in the selected location over 1981-2000. Frequencies are (a) 0.05 , (b) 0.08 , (c) 0.13 , and (d) $0.21 \mathrm{~Hz}$. The colors denote the directions corresponding to the arrows in Fig. 1a. It is noted that the $y$ axes in different panels are at different scales.

the seasonal mean wave spectra. The four seasons are organized as December-February (DJF), March-May (MAM), June-August (JJA), and September-November (SON). The spectral standard deviations (STDs) and long-term trends for each spectral bin are computed. To analyze the relationship between the local spectral wave climate and climate oscillations, the correlations between the time series of energy for each spectral bin and these climate indices are computed, resulting in "directional spectra" of correlation coefficients.

\section{d. Wind projections and relationship to wave spectra}

The evolution of wind-wave energy is a complex process and is represented by the wave action balance equation in numerical wave models. From a statistical point of view, however, the distribution of spectral wave energy at a given location is determined by the wind field in a certain region. For instance, the regions with potential impacts on the wave spectra at Point $X$ are shown in Fig. 1. However, it is noted that not all the winds in these regions can leave their signals on the wave spectra at that location. For instance, winds blowing in the directions opposite to the directions in Fig. 1c will not generate any wave energy that can reach Point X. Considering that wind-generated wave energy is positively correlated with the wind component in the wave propagation direction, the projection of the wind vector on the direction pointing to the target point (hereafter, wind projection) is employed to link the basin-scale wind field with the local wave spectra:

$$
U_{\text {proj }}=\operatorname{MAX}\left[0, U \cos \left(\theta_{U}-\theta_{A}\right) \delta\right],
$$

where $U$ is the $10-\mathrm{m}$ wind speed, $\theta_{U}$ is the direction of the wind, $\theta_{A}$ is the azimuth direction from a geographical location to the target point, and $\delta$ is the land blocking factor, which equals 0 (1) if the great circle between the location and the target point is (not) blocked by land. For any given point in the ocean, such as Point $\mathrm{X}$ in this study, the corresponding wind projections at different geographical locations also make up a 3D array $U_{\text {proj }}(t, \varphi, \lambda)$ covering the global ocean. 

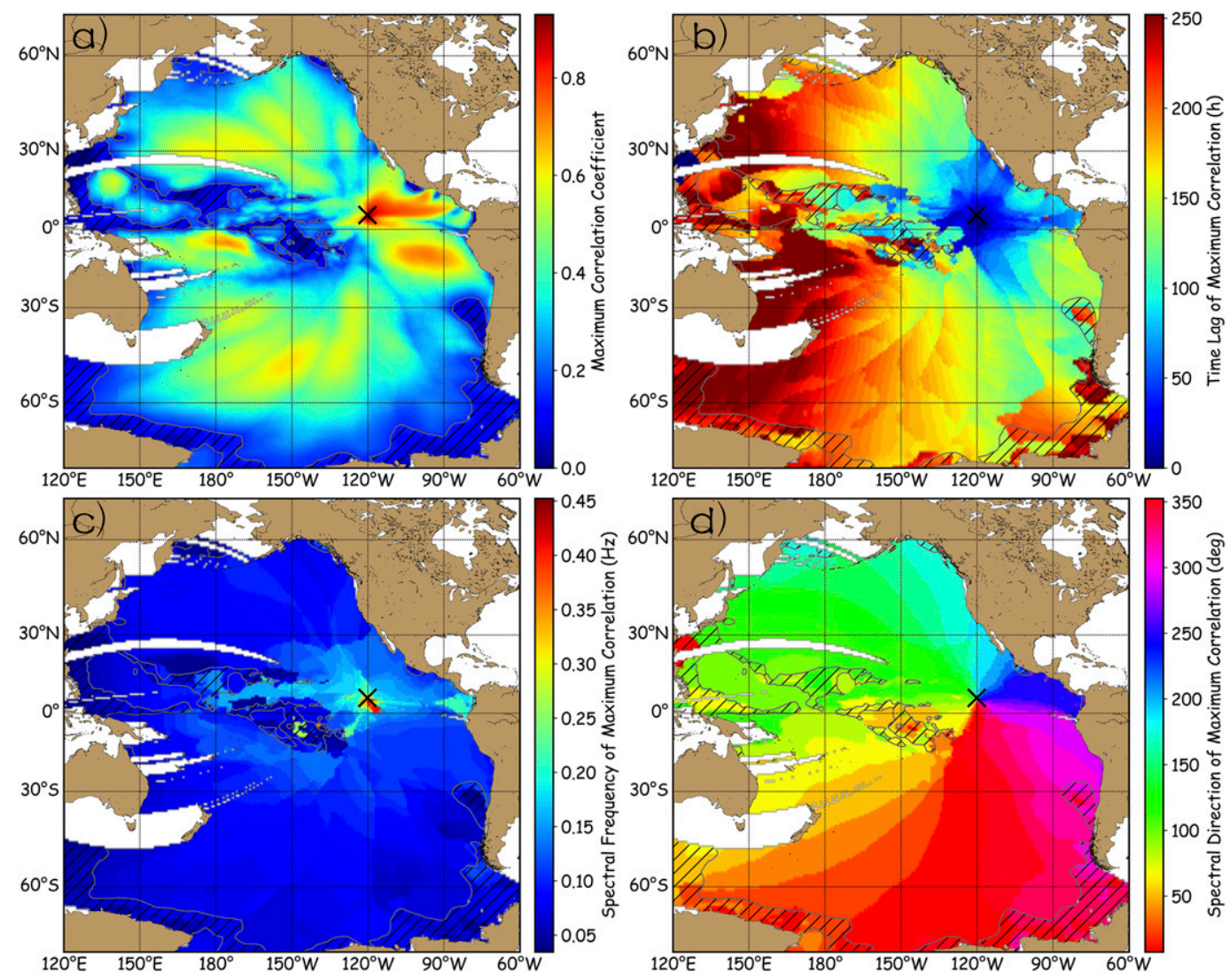

FIG. 3. The geographical distributions of (a) maximum cross-correlation coefficients between the wave spectrum and wind projections for Point $\mathrm{X}$ (the cross) and the distributions of (b) time lag, (c) spectral frequency, and (d) spectral direction corresponding to the maximum correlation. Coefficients not significant at the $99 \%$ confidence level are shaded by slashes.

The normalized cross-correlation array between the local wave spectra and the corresponding wind projection array is calculated for Point $\mathrm{X}$ to illustrate the effectiveness of the wind projection:

$$
r(\tau, f, \theta, \varphi, \lambda)=\frac{\sum_{t=1}^{n}[G(t-\tau, f, \theta)-\bar{G}(f, \theta)]\left[U_{\text {proj }}(t, \varphi, \lambda)-\overline{U_{\text {proj }}}(\varphi, \lambda)\right]}{\sqrt{\sum_{t=1}^{n}[G(t-\tau, f, \theta)-\bar{G}(f, \theta)]^{2}} \sqrt{\sum_{t=1}^{n}\left[U_{\text {proj }}(t, \varphi, \lambda)-\overline{U_{\text {proj }}}(\varphi, \lambda)\right]^{2}}}
$$

where $\tau$ is the lag time between the spectral series and wind projection series, which is introduced here because the wave generated by the remote wind takes time to propagate to the target point. At latitude $\varphi_{n}$ and longitude $\lambda_{n}$, the values of $r\left(\tau, f, \theta, \varphi_{n}, \lambda_{n}\right)$ can be interpreted as a $3 \mathrm{D}$ matrix of correlation coefficients between the wind projections and the spectral densities in all spectral bins $(f$ and $\theta)$ with different time differences $\tau$. The maximum value of $r\left(r_{\max }\right)$ is therefore regarded as the correlation value between wind projection at $\left\langle\varphi_{n}, \lambda_{n}\right\rangle$ and the wave spectra at Point $\mathrm{X}$. The $\tau$ corresponding to $r_{\text {max }}$ can be used to define the average travel time for generated waves to propagate from different locations to Point $\mathrm{X}$, while another definition of average travel time of waves is given by Pérez et al. (2014). Figure 3a shows the spatial distribution of correlations between the wind projections and the wave spectra at Point X, and the values of $\tau, f$, and $\theta$ that correspond to $r_{\max }$ are shown in Figs. 3b-d, respectively.

The garden sprinkler effect-like pattern in Fig. 3a and the discontinuous edges in Figs. 3b-d are due to the discreteness of spectral frequency and direction bins, 
which can be reduced using the spectra with a higher resolution. Unsurprisingly, the highest $r_{\max }$ is observed in the region close to Point $\mathrm{X}$ with the highest values of more than 0.9. In this region, the time lag between the wind and wave is generally within $50 \mathrm{~h}$, and the wind projection is correlated with wind-sea energy at frequencies higher than $0.15 \mathrm{~Hz}$. However, it is noted that there is no strict definition of when wind seas turn into swells. Except for the wind exactly at Point X, the wave energy generated anywhere in the ocean, no matter how close or far, needs some time to arrive at Point X, leading to the time lag always being larger than zero. Outside this region, the maximum correlations between the wind projections and the wave spectra at Point $\mathrm{X}$ are relatively lower, but statistically significant correlations (with a $P$ value of 0.01 ) are found over almost all of the Pacific Ocean, except in the tropical central Pacific. The correlation coefficients are greater than 0.6 in the trade wind zone to the southeast of Point $\mathrm{X}$ and are greater than 0.5 in the storm track regions at midlatitudes and the tropical west Pacific, which are thousands of kilometers away. The $r_{\max }$ in these regions preliminarily corresponds to relatively low frequencies, and the corresponding time lags (travel time for the wind signals) generally increase with distances. The spectral directions corresponding to the $r_{\max }$ (Fig. 3d) show a pattern of rotation around Point $\mathrm{X}$, which is in line with the azimuth directions in Fig. 1b. These results indicate that the signals of the wind field, both local and remote, can be recorded by local wave spectra, and the spectral densities of each frequency and direction can be statistically linked with the wind projections from a certain geographical region. Therefore, the wind projection can be employed as the parameter to describe the connections between wind climate and spectral wave climate. The annual mean, seasonal mean, long-term trends, and correlations with climate indices of $U_{\mathrm{proj}}(t, \varphi, \lambda)$ are computed to evaluate their climatological relationship to the wave spectra at Point $\mathrm{X}$.

\section{Results and discussion}

\section{a. Linking spectral wave climate with wind climate}

The annual mean wave spectrum of the selected location is displayed in Fig. 4a. There are four energy peaks at $\left\langle 0.07 \mathrm{~Hz}, 20^{\circ}\right\rangle,\left\langle 0.07 \mathrm{~Hz}, 135^{\circ}\right\rangle,\left\langle 0.14 \mathrm{~Hz}, 240^{\circ}\right\rangle$, and $\left\langle 0.12 \mathrm{~Hz}, 320^{\circ}\right\rangle$, which correspond to four wave climate systems. Here, these four systems are labeled as Systems A-D, respectively. To analyze whether these systems are wind sea related or swell related, the correlation coefficients between local wind projections and the spectral densities in each spectral bin are computed, and the results are shown in Fig. 4b. The azimuth direction $\theta_{A}$ in Eq. (4) is not applicable for local winds; thus, it is defined as the direction in the spectrum. This correlation coefficient can be employed as an indicator to describe whether the sea state is wind sea dominated or swell dominated from a statistical point of view: a high correlation between wind speed and wave energy means the waves are strongly coupled to the local wind so that it corresponds to wind seas, and vice versa for swells. As expected, although apparent anisotropy can be observed in the distributions of correlation coefficients, the high-frequency part of the spectrum generally has relatively high correlations with the local winds. Systems A and B have low frequencies and sharp energy peaks, and their correlations with the local winds are less than 0.1 , which means that most of their energy is swell related coming from far fields. The correlations between local winds and most spectral bins of Systems $\mathrm{C}$ and $\mathrm{D}$ are greater than 0.5 , and these two systems have higher frequencies and wider directional spreads. Therefore, they are more wind sea related than Systems $\mathrm{A}$ and $\mathrm{B}$. However, it is also noted that there is no strict distinction between wind seas and swells. The lowfrequency components of Systems C and D also show low correlations of less than 0.3 , indicating that some of the energy in these two systems is also swell related. The annual mean wave spectrum shows that there could be more than one wind sea-related system and two swellrelated systems coexisting in the wave climate at the same point. The values of $H_{m 0}, T_{m-1,0}$, and $\theta_{m}$ corresponding to the annual mean wave spectrum are $2.13 \mathrm{~m}$, $10.4 \mathrm{~s}$, and $14.5^{\circ}$, respectively. Clearly, these integrated parameters cannot adequately describe the wave climate even if wind seas and swells are treated separately.

The spectral STD (Fig. 4c) shows the degree of scattering of spectral densities in each frequency and direction bin. The pattern of the spectral STD is similar to that of the annual mean wave spectrum, which means the frequency and direction with higher mean wave energy usually also have higher variability of wave energy. Meanwhile, there are also some differences between the two patterns. The annual mean wave spectrum of System A is more energetic than that of System B in Fig. 4a, but the spectral STD of System B is larger than that of System A in Fig. 4c. The fast Fourier transform is applied to the time series of the spectra to extract the amplitude of annual cycle for each frequency and direction bin, with results shown in Fig. 4d. The annual amplitude of spectral density is much larger for System B than System A, showing that the larger spectral STD of System B is primarily due to the more intense seasonality of the swells coming from the $\mathrm{NH}$ than those from the Southern Hemisphere (SH). Both of the wind 

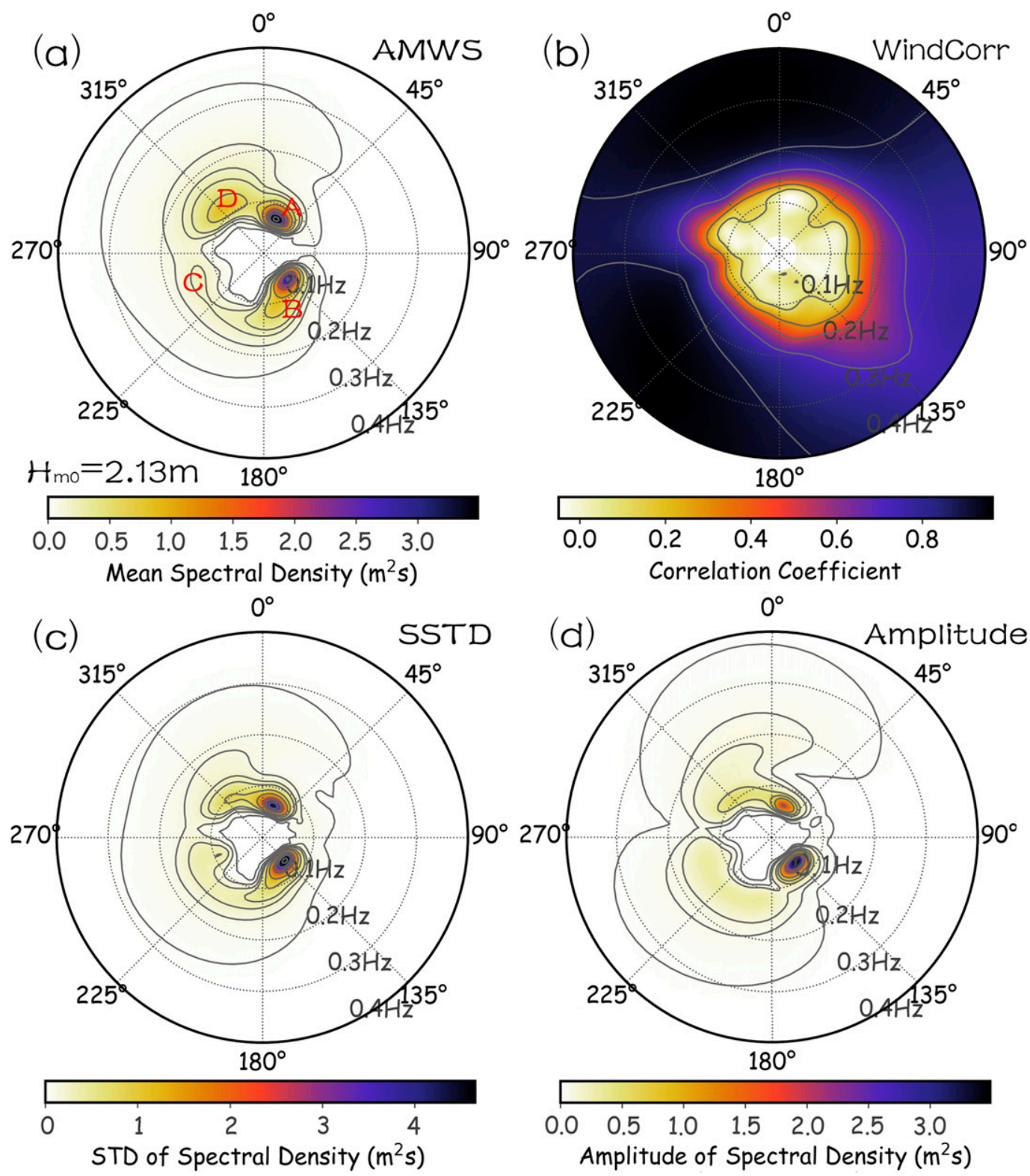

FIG. 4. The (a) annual mean wave spectra (with the four wave climate systems marked in red letters), (b) correlations with local winds, (c) spectral STDs, and (d) amplitudes of annual cycle for the selected point. The four identified wave climate systems, A-D, are marked in (a). A direction of $0^{\circ}$ corresponds to the wave energy propagating toward the north (for all coordinates of wave spectra in this paper).

sea-related peaks in the spectral STD, C and D, are observed in lower frequencies than those in the pattern of annual mean wave spectrum. The annual mean wave spectra and spectral STD are computed at some other points (not shown here), and this phenomenon is well defined for nearly all wind sea systems, indicating that spectral densities of wind sea-related systems are usually more scattered in the low-frequency parts. This is because the energy of the high-frequency part of the wave spectrum is more stable (closely following the $f^{-n}$ ) during the growth of wind seas. Another noteworthy feature is that the spectral STD values are usually greater than the values of annual mean wave spectrum in most of the spectral bins (the maximum of spectral STD is also larger than the maximum of annual mean wave spectrum). As the values of spectral density are never less than zero, the relatively large STDs mean that the distributions of spectral densities generally have high skewness and long tails, which is confirmed by the probability density function (not shown here). 

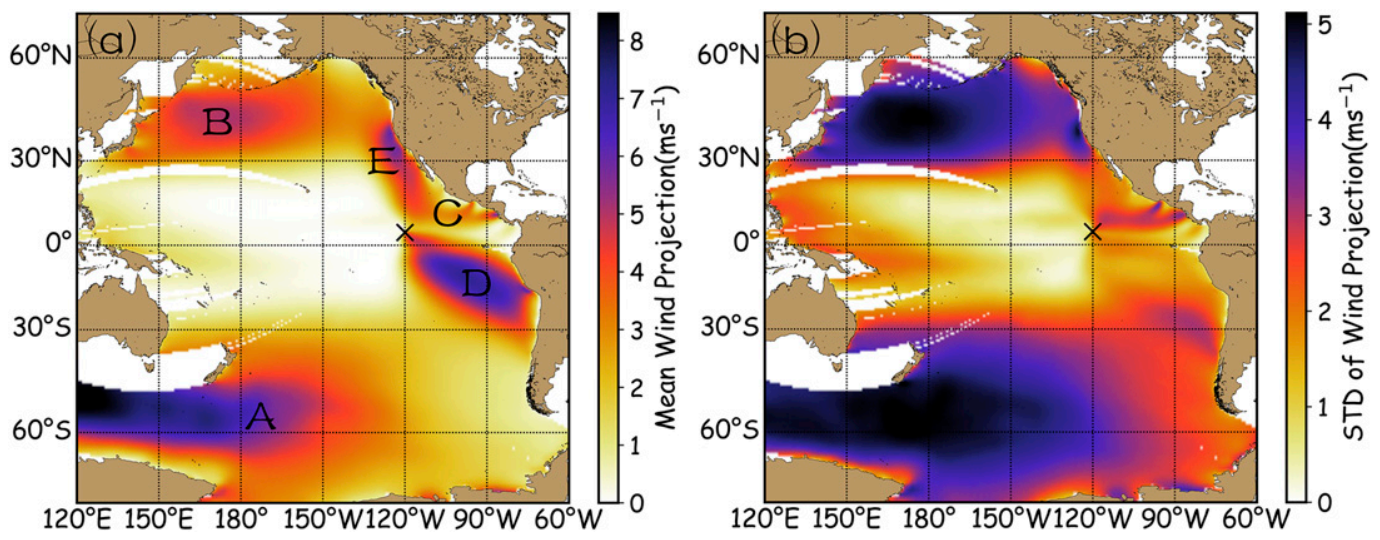

FIG. 5. The geographical distributions of (a) annual mean wind projections and (b) wind projection STD for Point X (the cross). The source regions of the five wave climate systems are marked in (a).

Since wind projections and wave spectra are correlated, the climatology of wind projections should also be in line with the climatology of wave spectra. The spatial distributions of the annual mean and the STD of the wind projections for Point $X$ are displayed in Figs. 5a and $5 \mathrm{~b}$, respectively. For all the wave climate systems in Fig. 4, their respective origins are clearly shown in Fig. 5a. The origins of swells in different parts of the global ocean have been identified by Alves (2006) and are in line with the results here. Meanwhile, the method described in this paper is able to identify the wave energy source for a given target point, which provides a perspective different from Alves (2006). The main sources of wave energy include the westerlies and trade wind zones in both hemispheres. Regions with high wind projections in the westerlies in the $\mathrm{SH}$ and $\mathrm{NH}$ are the sources of the energy in Systems A and B in Fig. 4a, respectively. Although the distance from Point $X$ to the source region of System B is a bit larger than the distance to the source region of System A, the wind projections are significantly larger in the $\mathrm{SH}$, resulting in the mean energy of System A being higher than System B. The trade winds along South America, which correspond to System D in Fig. 4a, are another important source region for waves at Point $\mathrm{X}$ and are better defined than the trade winds in the NH in Fig. 5a. For this reason, System D is better defined than System C in Fig. 4a. Another noteworthy feature in Fig. 5a is the wind projections for the California low-level coastal jet (CLCJ; Burk and Thompson 1996), which are clearer than the projections of the trade winds in the NH. However, the corresponding wave system of the CLCJ is not directly observed in the annual mean wave spectrum because the direction of the wave energy from CLCJ to Point $\mathrm{X}$ overlaps with the wave energy from the westerlies in the NH. In the atlas of global spectral wave climate [Portilla (2018); the product is available at http://www.modemat.epn.edu.ec/nereo/], the wave system corresponding to CLCJ (hereafter System E) is well defined in the long-term probability density distribution of wave partitions (PDDWP). As pointed out by Portilla et al. (2015b), the annual mean wave spectrum is usually smoother than the PDDWP. Therefore, not all single wave systems, especially those with relatively low energy, are recognizable in the annual mean wave spectrum. Meanwhile, the signature of System E is still vaguely observed from the asymmetry of the spectral densities near System B: because of the energy from System E, the right side of System B along the propagation has more energy than the left side.

The STDs of wind projections show a pattern similar to the mean wind projections. The largest variability of wind projections is found in the westerlies of both hemispheres with similar values of STD, corresponding to the high spectral STD of Systems A and B. In this case, the source region of System B is closer to Point X than that of System A, which explains System B's higher values because a larger distance means large energy attenuation due to the angular spreading effect. The variability of CLCJ is also significant, but its signature in the spectral STD is also partially overwhelmed by System B. The trade winds in both hemispheres in Fig. 5b are still observable but not as clear as they are in Fig. 5a, which is also in line with the relatively vague signals of Systems C and D in the spectral STD at Point X.

\section{b. Seasonal variability}

The seasonal mean wave spectra at the selected point are displayed in Fig. 6. The two swell systems A and B in Fig. 4a show opposite phases peaking in JJA and DJF, respectively. System A, which originates from the extratropical storm track in the $\mathrm{SH}$, is well defined over the entire year, but its energy is significantly lower in DJF than in the other three seasons because wind storms in 

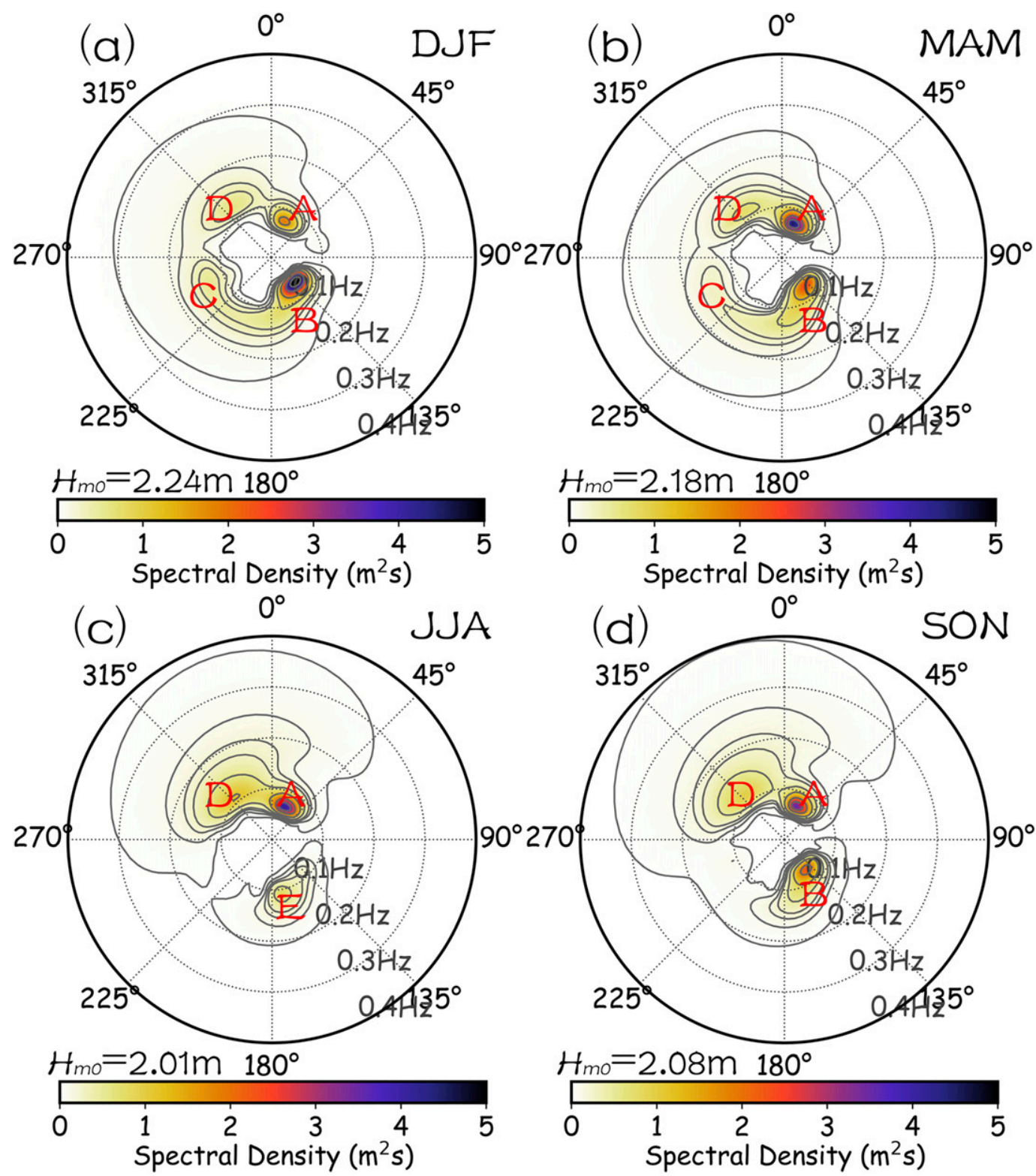

FIG. 6. Seasonal mean wave spectra for the selected point in (a) DJF, (b) MAM, (c) JJA, and (d) SON. It is noted that the color scales are different for different panels. A direction of $0^{\circ}$ corresponds to the wave energy propagating toward the north.

the $\mathrm{SH}$ are the weakest in DJF. System B shows a stronger seasonality (as shown in Fig. 4d) with the highest wave energy in DJF, while it almost disappears in JJA when the swells from the westerlies in the North Pacific cannot propagate to Point X. Meanwhile, System $\mathrm{E}$, which is generated by the CLCJ, is clearly identified at $\left\langle 0.12 \mathrm{~Hz}, 170^{\circ}\right\rangle$ in JJA, as shown in Fig. 6c. The other two wave climate systems, $\mathrm{C}$ and $\mathrm{D}$, also show opposite phases with respect to seasonal variability. These two systems are generated by the trade winds from different hemispheres, which are stronger in the corresponding hemispheric winter due to the seasonal shift of the ITCZ. System C is clearly observed in DJF and is still identifiable from the outline of the contours in MAM, but it almost disappears in JJA and SON, indicating that the northeast trade winds in the $\mathrm{NH}$ generally cannot impact the wave state at Point $\mathrm{X}$ during the boreal summer and autumn. System D is observed in all four seasons due to the potential long fetch of southeast trade winds to Point $\mathrm{X}$ even in DJF and MAM, but its energy is significantly higher in JJA and SON. Although clear seasonality of the spectra is observed for all wave 

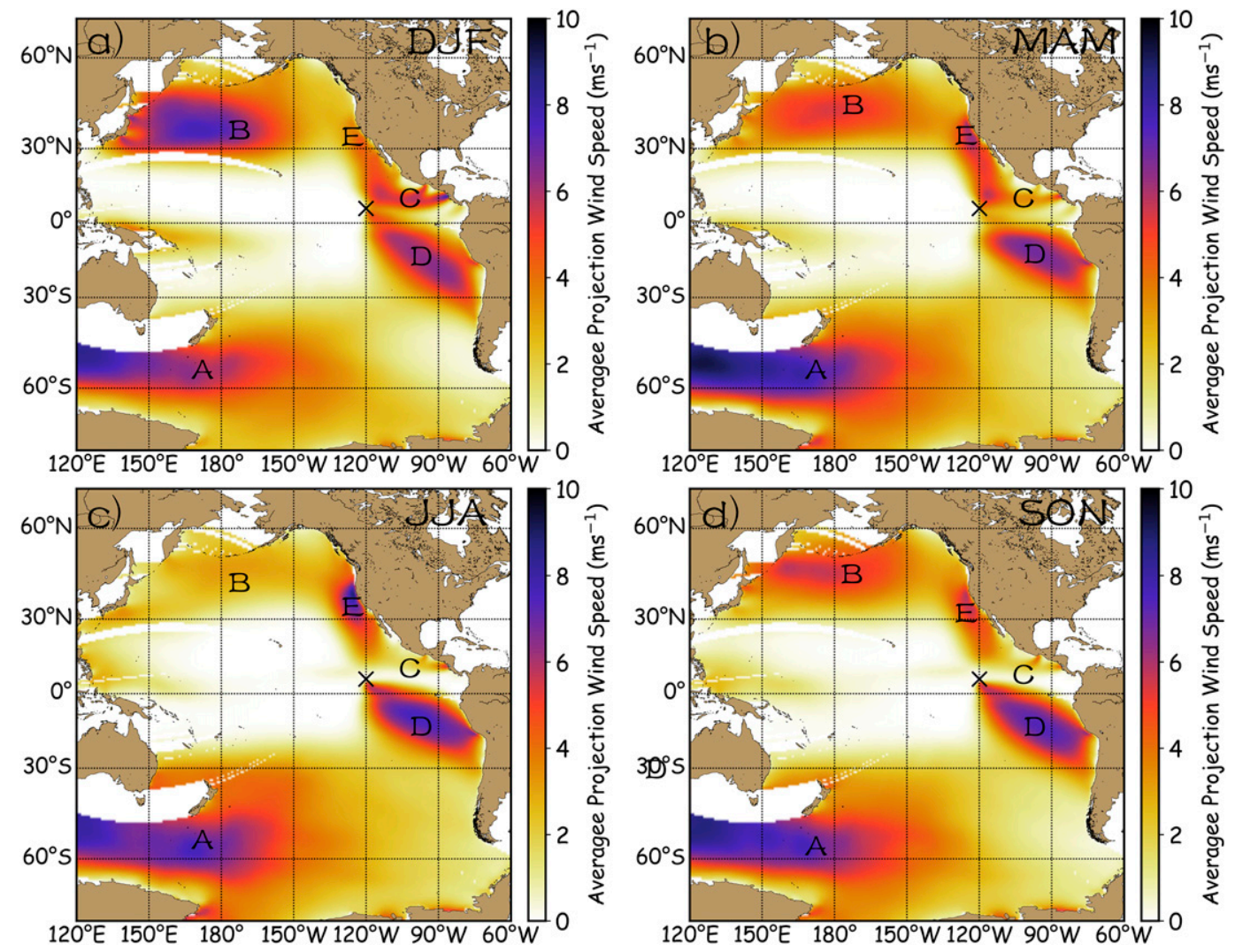

FIG. 7. The geographical distributions of seasonal mean wind projections for Point $\mathrm{X}$ (the cross) in (a) DJF, (b) MAM, (c) JJA, and (d) SON.

climate systems, the seasonality of SWH is not as clear due to the cancellation effect of the phase-opposite variations of these systems: the mean total SWH at Point $\mathrm{X}$ is the highest in DJF $(2.24 \mathrm{~m})$ and the lowest in JJA $(2.01 \mathrm{~m})$, with a difference of only $0.23 \mathrm{~m}$.

The seasonal mean wind projections for Point $\mathrm{X}$ are displayed in Fig. 7. In line with the seasonal mean wave spectra of System A in Fig. 6, the seasonality of the wind projections in the westerlies of the $\mathrm{SH}$ is relatively low. On the one hand, the maximum values of wind projection in this region are similar across all four seasons. On the other hand, the extent of the fetch in DJF is the smallest among the four seasons, leading to the least energy propagating into Point $\mathrm{X}$ during that time. It is noted that the wind speed in the westerlies in the Southern Ocean to the south of Australia and New Zealand should be significantly higher in JJA than in DJF, but the variability of wind speed is mainly in the component perpendicular to the great circle [Fig. 1 of Semedo et al. (2011)]. Thus, the seasonal variability of wind speed in this region has little influence on the energy of System A. The maximum values for trade wind projections along South America are $\sim 6 \mathrm{~m} \mathrm{~s}^{-1}$ in DJF and MAM and $\sim 7 \mathrm{~m} \mathrm{~s}^{-1}$ in JJA and SON.
Meanwhile, the ITCZ moves to a position to the north of the equator in JJA and SON so that the fetch of trade winds is also closer to Point $\mathrm{X}$ in JJA and SON than in DJF and MAM (Fig. 7). Both reasons explain the seasonal variability of System D in Fig. 6. In contrast, the seasonality of the wind projections in the $\mathrm{NH}$ is much greater. The seasonal shift of the ITCZ makes the trade wind projections in the NH clearer in DJF and MAM, but they become vague in JJA and SON, which is also in good agreement with the seasonal variability of System C. Reaching their maximum in DJF, the wind projections in the westerlies of the $\mathrm{NH}$ exhibit strong seasonality in agreement with the seasonal variability of System B. In JJA, the signature of the westerlies in the $\mathrm{NH}$ is not observable while the wind projections of the CLCJ are the strongest, resulting in the disappearance of System B and the appearance of System E in Fig. 6c. Another feature of the $\mathrm{NH}$ westerlies with respect to the wind projections is the northward shifting during SON in Fig. 7, which corresponds to the shift of the spectral peak of System B from $\sim 135^{\circ}$ in DJF to $\sim 150^{\circ}$ in SON (Fig. 6). For regions where the wind projections are small in magnitude but highly correlated to the spectra in Fig. 3 (e.g., a correlation of $0.6 \sim 0.7$ can be observed in 


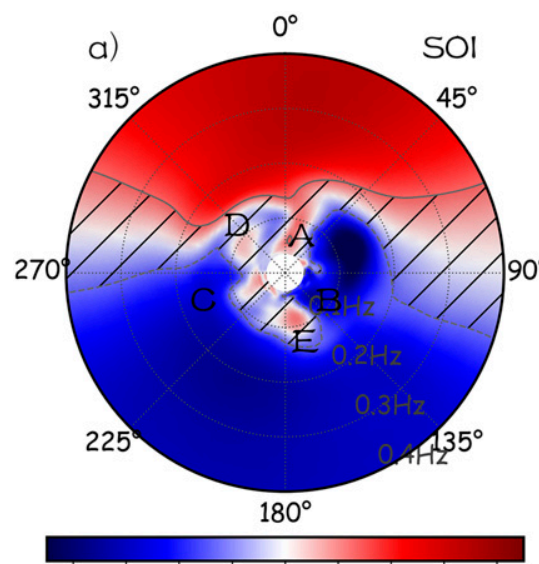

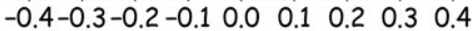

Correlation Coefficient

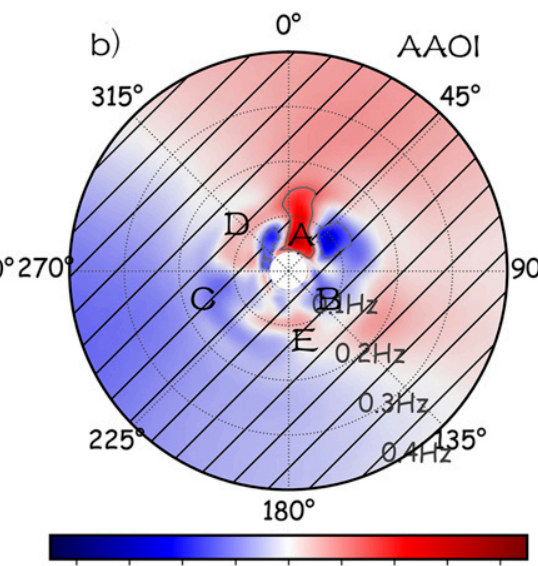

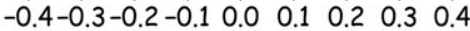

Correlation Coefficient

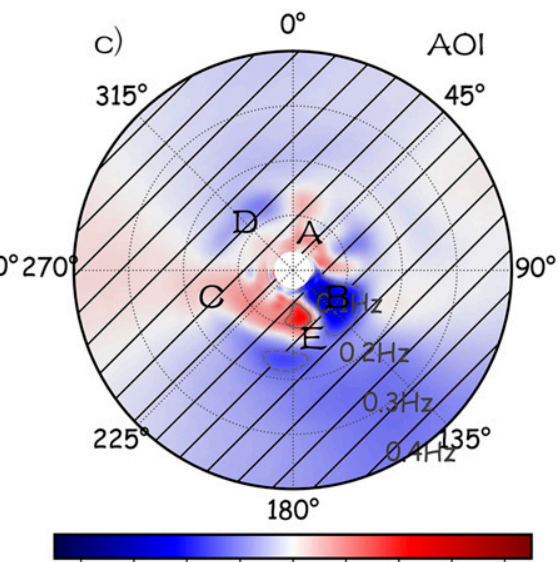

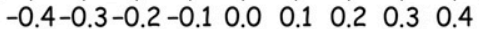

Correlation Coefficient

FIG. 8. Correlation coefficients of the monthly averaged wave spectra with the (a) SOI, (b) AAOI, and (c) AOI at Point X. Coefficients not significant at the $99 \%$ confidence level are shaded by slashes.

the western Pacific), the impacts of the wind climate on the spectral wave climate are not directly observable with respect to seasonal variability. However, such impacts might be distinguished from the interannual variability, as shown in the following.

\section{c. Interannual variability}

To analyze the link between the local spectral wave climate and large-scale climate oscillations, correlation coefficients are computed between the anomalies of monthly averaged spectral densities and the three universally accepted climate indices described in section 2 for all spectral grids (Fig. 8). The anomaly of the monthly average is defined as

$$
A_{y, m}(f, \theta)=\overline{G_{y, m}}(f, \theta)-\overline{G_{m}}(f, \theta)
$$

to eliminate the impact of seasonal variability, where $\overline{G_{y, m}}$ is the monthly mean of year $y$ and month $m$, and $\overline{G_{m}}$ is the mean of month $m$ for all years. The corresponding correlation coefficients between the monthly averaged wind projection anomalies and the climate indices are displayed in Fig. 9.

Significant correlations are observed between the wave spectra and the climate indices as well as between the wind projections and the climate indices. It is noted that the identified wave climate systems and their respective source regions are not well defined in Figs. 8 and 9 (also in Fig. 10). Therefore, the labels in Figs. 8-10 are simply marked according to the patterns in Figs. 4-7, which should only serve as a reference for the positions of the wave climate systems and their sources. In Fig. 8a, the highest correlation with SOI $(r \approx-0.5)$ is observed near $\left\langle 80^{\circ}, 0.13 \mathrm{~Hz}\right\rangle$, which is a swell-related spectral regime because the correlation for this region in Fig. 4b is less than 0.3. Significant correlation coefficients of $\sim \pm 0.4$ are found in the wind sea-related high-frequency regime of the spectrum with opposite phasing between the northward and southward directions. The energy of Systems A, D, and E is not significantly correlated with the SOI. In contrast, the regime corresponding to the peak of System B significantly correlates negatively with the SOI $(r \approx-0.4)$. In Fig. 9a, a well-marked feature is the strong negative correlation $(r \approx-0.7)$ in the western equatorial Pacific, which appears to correspond to the strongest negative values near $\left\langle 80^{\circ}, 0.13 \mathrm{~Hz}\right\rangle$ in Fig. 8a. Although the predominant winds are westward in this region, eastward winds also occur sometimes, especially in DJF, as shown in Fig. 7a, and the waves generated by them are able to reach Point X, as shown in Fig. 12 of Alves (2006). The correlation coefficients between the wind projections in the western equatorial Pacific and the wave energy in the aforementioned spectral regime can reach up to 0.7 (Fig. 3), also demonstrating that the eastward wave energy is able to propagate to Point $\mathrm{X}$. Therefore, the strengthened (weakened) eastward winds in this region during El Niño (La Niña) events lead to stronger (weaker) eastward wave energy at Point X, resulting in the negative correlations with the SOI. The other spectral regions with significant correlation coefficients in Fig. 8a can also find their sources in Fig. 9a. The significant correlation in the high-frequency regime of Fig. 8a is in agreement with the dipole-like pattern of the wind projections near Point $\mathrm{X}$, showing that the southward (northward) component of the local winds is stronger during the El Niño (La Niña) event. Besides, the El Niño (La Niña) event corresponds to stronger (weaker wind) in the North Pacific westerlies, 

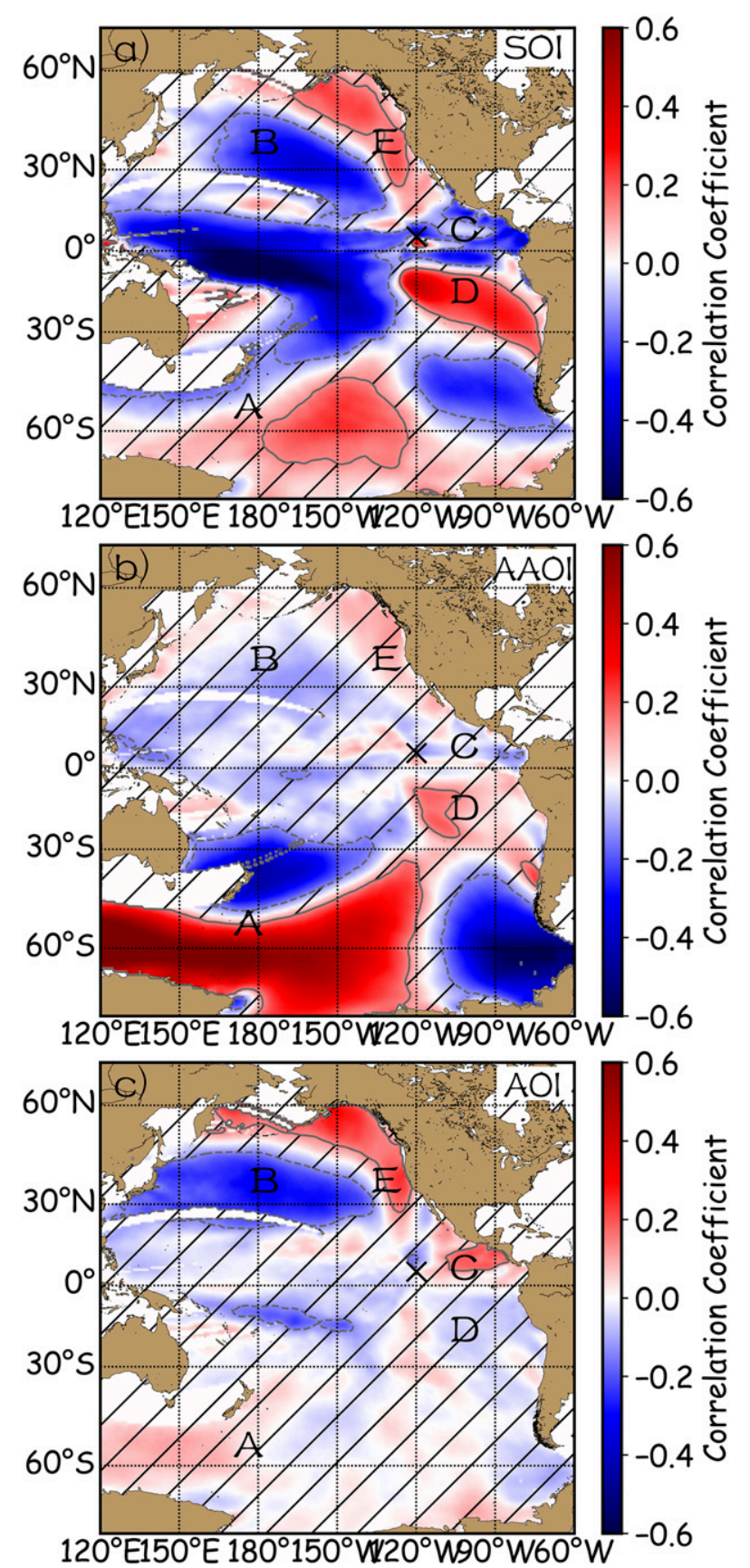

FIG. 9. Geographical distributions of correlation coefficients of the monthly averaged wind projections with the (a) SOI, (b) AAOI, and (c) AOI for Point X (the cross). Coefficients not significant at the $99 \%$ confidence level are shaded by slashes.

which is in line with the negative correlations between the energy anomalies of System B and SOI.

However, not all the regions with significant correlation coefficients with SOI in Fig. 9a can find their signatures in Fig. 8a. For instance, the trade winds along the coast of South America are weaker during El Niño years due to the anomalies of eastward wind, which also lead to weaker wind projections to Point X. Thus, most of the trade wind zone in this region is positively correlated with the SOI. Meanwhile, the mean position of the ITCZ moves southward during El Niño years, causing the north part of this trade wind zone to have negative correlations with the SOI. Because of the cancellation of the northern part of the trade winds, the correlations between the spectrum and the SOI are not significant for System $D$. There are also two regions with significant but weak positive correlation coefficients $(r \approx 0.2)$ in the high latitudes of both hemispheres in Fig. 9a. After the propagation of large distances, however, the wave energy generated by them only has insignificant positive correlations with the SOI in low-frequency regimes around $10^{\circ}$ and $170^{\circ}$.

The correlation values of the wave spectra at Point $X$ with the AAOI and AOI are generally lower than with the SOI, and significant correlations are mostly found at low frequencies dominated by swells. For AAOI, significant correlations are only observed in the northern half of the spectrum with the largest positive correlations $(r \approx 0.35)$ near the peak of System A, while significant negative correlations are found on both sides of this regime. This low-high-low pattern is in good agreement with the wind projections to the south of $30^{\circ} \mathrm{S}$ in Fig. 9b, although the correlation coefficients are significantly lower in Fig. 8b after the long-distance propagation of wave energy. When the AAO is in the positive phase, the westerly wind belt intensifies and contracts toward Antarctica. Stronger westerlies correspond to higher (lower) wind projections to Point $\mathrm{X}$ to the west (east) of $120^{\circ} \mathrm{W}$. Thus, the wind projections in the westerly wind belt also show strong positive/negative correlations $(r \approx \pm 0.65)$ with the AAOI to the west/east of $120^{\circ} \mathrm{W}$. Meanwhile, the wind projection in the north of the westerly wind belt in the SH shows a significant negative correlation with AAOI due to the shifting of the westerly wind belt with the phase of AAO.

Symmetry can be observed between the correlations of the wave spectra with AOI and those with AAOI. Significant correlations are located only on the southern half of the spectrum for AOI in Fig. 8c, especially in the southeast quadrant, indicating that the AAO and AO mainly impact the swells propagating northward and southward, respectively, in the tropical Pacific Ocean. Significant negative correlations $(r \approx-0.3)$ are found near the peak of System B, and positive correlations are found in the low-frequency part of $180^{\circ}$. This pattern is also in good agreement with Fig. 9c, where AO's impact on the wind projections is mostly reflected in the regions to the north of $30^{\circ} \mathrm{N}$. The AO's impact on the westerly wind belt in the $\mathrm{NH}$ is similar to the AAO's in the 

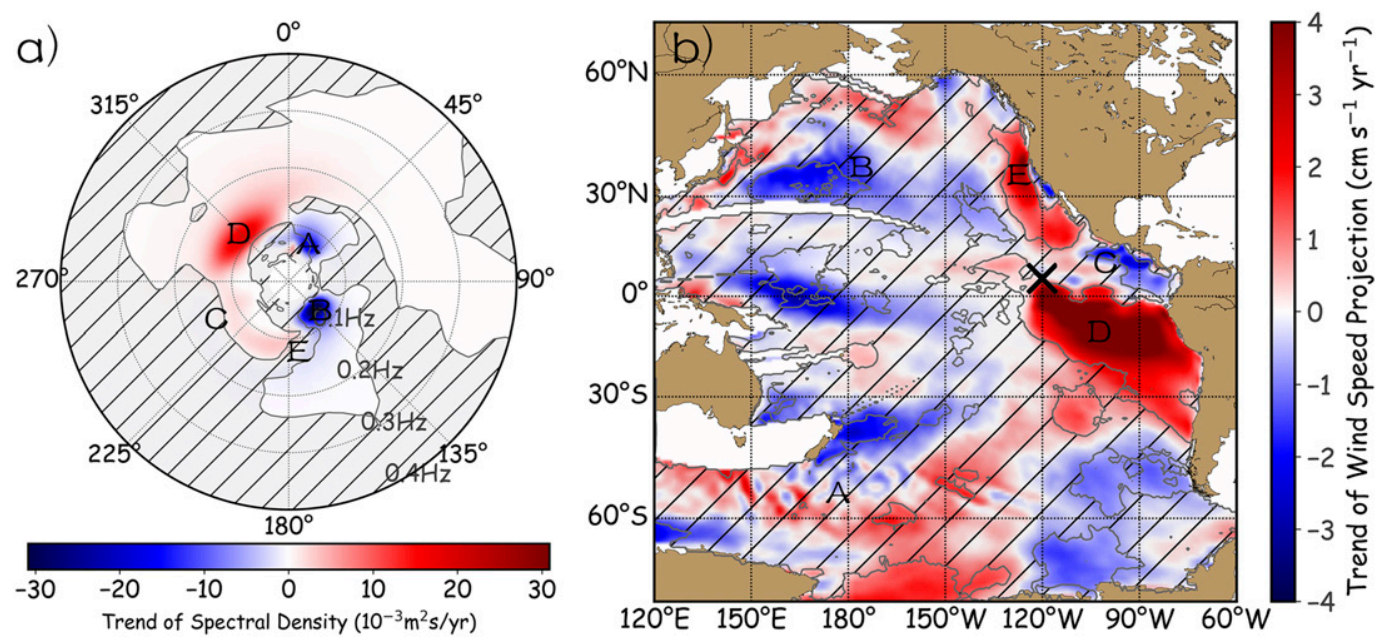

FIG. 10. Linear trends for (a) spectral densities and (b) wind projections for Point X over 1992-2017 with the trends not significant at the $95 \%$ confidence level shaded by slashes.

SH: the westerly wind belt intensifies and contracts toward the polar region in the positive phase of AAO. However, due to the presence of the North American continent and the Aleutian Islands, the area in Fig. 9c with positive correlation coefficients with AOI is much smaller than the corresponding region in Fig. 9b. Besides, the correlation values are lower $(r \approx 0.3)$ in Fig. 9c than in Fig. 9b, resulting in relatively small signatures in the spectrum of correlation (Fig. 8c). On the contrary, the area with negative correlation with AOI corresponding to the shifting of the westerly wind belt with the phase of $\mathrm{AO}$ is larger, which leads to a larger area of negative correlations in Fig. 8c.

\section{d. Long-term trends}

Because of the increase in global sea surface wind speeds, the global mean SWH is observed to increase over the last several decades (e.g., Aarnes et al. 2015; Young et al. 2011; Hemer et al. 2010). Wind and SWH trends are different across different regions and are not uniformly positive because of the inhomogeneity of wind speed increase and the propagation of swells. Meanwhile, the wave climate at a given location is composed of different wave systems, which might have different trends of wave energy. The distributions of spectral density linear trends at Point X, and the corresponding wind projection trends, are shown in Figs. 10a and 10b, respectively. The Mann-Kendall method is employed to calculate the trends and test their significance. It is noted that the use of reanalysis to describe trends is problematic because of the change in the quality and quantity of remote sensing observations assimilated into the data. Particularly, more observations are available from altimeters from 1991 onward, which produces spurious trends in the reanalysis data (Aarnes et al. 2015). Thus, only the trends over the period from 1992 to 2017 are computed here. During this period, the linear trend of SWH at Point X is not significant even at the $90 \%$ confidence level in the ERAInterim data. However, all four wave climate systems identified in Fig. 4 have significant increasing or decreasing trends, which implies that the trends of different wave systems neutralize the overall trend into an insignificant one. The spectral regimes of the two swellrelated systems A and B show significantly negative trends, while $\mathrm{C}$ and $\mathrm{D}$ show positive trends and System $\mathrm{E}$ shows no significant linear trend. The corresponding SWH trends for Systems A-D are $-1.7,-2.9,1.0$, and $3.2 \mathrm{~cm} \mathrm{yr}^{-1}$, respectively.

The pattern of the wind projection trends is relatively complicated, but their connections with the spectral trends can still be partially identified. It is noted that the increase (decrease) in the magnitude of wind projection does not necessarily mean the increase (decrease) in wind speed, as the change of wind direction also impacts the wind projection. The most obvious upward trends of the wind projections are found in the trade wind zone along the coast of South America, which is in good agreement with the largest increase of wave energy in System D. The trade winds in the $\mathrm{NH}$ also generally have a moderate upward trend, in line with the weak but significant increase of wave energy in System C. The corresponding source region of the swell system $\mathrm{B}$ in the westerlies of the $\mathrm{NH}$ also shows significant decreasing trends in wind projection (to the left of label $\mathrm{B}$ in Fig. 10b). However, the trends in wind projection in the source region of System A, the westerlies of the $\mathrm{SH}$, are not very clear. Both increasing and decreasing trends are 
observed in this region, with significant increasing wind projections to the east of New Zealand and significant decreasing wind projections around $60^{\circ} \mathrm{S}, 165^{\circ} \mathrm{W}$. Besides, the CLCJ region and the equatorial west Pacific also have significant increasing and decreasing trends, respectively, in wind projections. However, their signatures on the wave spectra are also not observable. There are two potential reasons for this problem. One is the cancellation effect along the route of wave propagation. For instance, the upward trends of wind projections in CLCJ might be canceled by the downward trends in the westerlies as they have similar arrival directions at Point X, while the downward trend in the equatorial west Pacific might be canceled by the upward trend of the eastward component of local winds. The other reason is that the data assimilation of winds and waves in the reanalysis is done independently, although they are coupled in the model, which might also lead to some inconsistencies between the trends of wind and waves, considering that the signal of these trends are relatively weak. It is noted that a time span of only 26 years is extremely short for linear trend calculation because the results are heavily impacted by interannual signals such as the ENSO cycle. Therefore, the results here can only be regarded as evidence of the link between wind projections and wave spectra with respect to linear trends.

\section{Summary and conclusions}

As waves can propagate over large distances, the wave spectrum at any location might contain some information about air-sea interactions in geographically distant regions. In this study, the spectral wave climate and its variability at a selected point in the tropical Pacific Ocean are characterized using 39-yr wave spectra over 1979-2017 from ERA-Interim. A simple parameter is defined as the projection of wind on the direction pointing to the given location in order to link the spectral wave climate and basin-scale wind climate. Significant correlations are observed between the wave spectra at the target point and the wind projections of both local and remote wind systems. The climatological wave spectrum at this point is constituted of five wave climate systems from different origins, which cannot be adequately described by integrated wave parameters even if wind seas and swells are treated separately. The seasonal and long-term variabilities of these wave climate systems are independent of each other, and significant correlations with the Southern Oscillation, the Arctic Oscillation, and the Antarctic Oscillation are observed in the local wave spectra, implying that the local wave spectra have rich climatic information. The wind field data from ERA-Interim illustrate that the generating areas of all wave climate systems in the climatological spectrum are well defined in the corresponding maps of wind projection climatology, confirming the effectiveness of this parameter (wind projection). The wind searelated (swell-related) energy in the higher (lower) frequencies of the spectra can be connected with the projections of local (distant) winds, and the footprints of corresponding seasonal and interannual variability and long-term trends of the wind climate are also found in the spectral wave climate. Therefore, the basin-scale wind climate and its variability are partially recorded by the wave spectra at a fixed point, and the wave spectra can be a potential indicator of the climate system.

The connection between the spectral wave climate at a given location and the wind climate in both the near and far fields can provide two ideas for future works. The first is that the wave spectra at any given location can be reconstructed from the corresponding wind projection. Consistent observational directional wave spectra with a record length of more than 30 years are still not available as far as we know, but the observational sea surface wind field has a long-term accumulation all over the ocean. Statistical methods can be used to build an empirical parametric model quantitatively linking the wave spectra and the wind projections over the period when both types of observational data exist. Then, historical directional wave spectra can be estimated from historical observational wind data using this model. Although such historical spectral wave information is also available from numerical wave model hindcasts, this type of parametric model can at least supplement the modeled results. Studies have been done using historical SLP data to reconstruct the wave spectra (e.g., Espejo et al. 2014; Rueda et al. 2017). Thus, we believe similar work could also be conducted using the historical wind (projection) information. The second idea is an opposite way of thinking in that the wind information can be monitored through the observation of wave spectra. Remote sensing and in situ observations of sea surface winds are available globally, but the observation of high-speed wind is still a challenge. The waves generated by high-speed winds will have intermediate or relatively low energy after propagating over large distances, and they can be observed with better accuracy. Thus, observational wave information might be used to retrieve local and remote wind information. Although it is difficult to directly establish a quantitative method to predict the remote wind information from local wave spectra due to the integral effect along wave propagation, some preliminary work has been done. For example, Hanson and Phillips (2001) developed a method to locate the storms in the ocean by backtracking the swell information at a fixed point using the dispersion 
relation, and Collard et al. (2009) developed a method to locate the storms by converging the backtracking trajectories of swell information measured by spaceborne synthetic aperture radar. Today, more and more data of observational wave spectra with better quality are available from buoys, ground wave radars, and spaceborne synthetic aperture radars, which is promising for a better understanding of global wind and wave climates.

Acknowledgments. The ERA-Interim data are downloaded by ECMWF web API. This work is jointly supported by the National Key Research and Development Program of China (Grant 2017YFC1404700), the National Natural Science Foundation of China (41806010), and the Discipline Layout Project for Basic Research of Shenzhen Science and Technology Innovation Committee (Grant 20170418). HJ and LM are also supported by the Fundamental Research Funds for the Central Universities, China University of Geosciences (Wuhan) (CUG170673), and the Guangdong Special Fund Program for Marine Economy Development (Grant GDME-2018E001), respectively. The three anonymous reviewers are greatly appreciated for their helpful comments and suggestions.

\section{REFERENCES}

Aarnes, O. J., S. Abdalla, J. R. Bidlot, and O. Breivik, 2015: Marine wind and wave height trends at different ERA-Interim forecast ranges. J. Climate, 28, 819-837, https://doi.org/10.1175/ JCLI-D-14-00470.1.

Alves, J. H. G. M., 2006: Numerical modeling of ocean swell contributions to the global wind-wave climate. Ocean Modell., 11, 98-122, https://doi.org/10.1016/j.ocemod.2004.11.007.

Anoop, T. R., V. S. Kumar, P. R. Shanas, and G. Johnson, 2015: Surface wave climatology and its variability in the north Indian Ocean based on ERA-Interim reanalysis. J. Atmos. Oceanic Technol., 32, 1372-1385, https://doi.org/10.1175/ JTECH-D-14-00212.1.

Ardhuin, F., B. Chapron, and F. Collard, 2009: Observation of swell dissipation across oceans. Geophys. Res. Lett., 36, L06607, https://doi.org/10.1029/2008GL037030.

Bromirski, P. D., D. R. Cayan, and R. E. Flick, 2005: Wave spectral energy variability in the northeast Pacific. J. Geophys. Res., 110, C03005, https://doi.org/10.1029/2004JC002398.

Burk, S. D., and W. T. Thompson, 1996: The summertime low-level jet and marine boundary layer structure along the California coast. Mon. Wea. Rev., 124, 668-686, https://doi.org/10.1175/ 1520-0493(1996)124<0668:TSLLJA > 2.0.CO;2.

Chen, G., B. Chapron, R. Ezraty, and D. Vandemark, 2002: A global view of swell and wind sea climate in the ocean by satellite altimeter and scatterometer. J. Atmos. Oceanic Technol., 19, 1849-1859, https://doi.org/10.1175/1520-0426(2002)019<1849: AGVOSA $>2.0 . \mathrm{CO} ; 2$.

Collard, F., F. Ardhuin, and B. Chapron, 2009: Monitoring and analysis of ocean swell fields from space: New methods for routine observations. J. Geophys. Res., 114, C07023, https:// doi.org/10.1029/2008JC005215.
Dee, D., and Coauthors, 2011: The ERA-Interim reanalysis: Configuration and performance of the data assimilation system. Quart. J. Roy. Meteor. Soc., 137, 553-597, https:// doi.org/10.1002/qj.828.

Earle, M. D., K. E. Steele, and D. W. C. Wang, 1999: Use of advanced directional wave spectra analysis methods. Ocean Eng., 26, 1421-1434, https://doi.org/10.1016/S0029-8018(99)00010-4.

Espejo, A., P. Camus, I. J. Losada, and F. J. Méndez, 2014: Spectral ocean wave climate variability based on atmospheric circulation patterns. J. Phys. Oceanogr., 44, 2139-2152, https://doi.org/ 10.1175/JPO-D-13-0276.1.

Fan, Y., S. Lin, I. M. Held, Z. Yu, and H. L. Tolman, 2012: Global ocean surface wave simulation using a coupled atmospherewave model. J. Climate, 25, 6233-6252, https://doi.org/10.1175/ JCLI-D-11-00621.1.

- I. M. Held, S. Lin, and X. Wang, 2013: Ocean warming effect on surface gravity wave climate change for the end of the twenty-first century. J. Climate, 26, 6046-6066, https://doi.org/ 10.1175/JCLI-D-12-00410.1.

— , S. Lin, S. M. Griffies, and M. A. Hemer, 2014: Simulated global swell and wind-sea climate and their responses to anthropogenic climate change at the end of the twenty-first century. J. Climate, 27, 3516-3536, https://doi.org/10.1175/ JCLI-D-13-00198.1.

Gemmrich, J., B. Thomas, and R. Bouchard, 2011: Observational changes and trends in the northeast Pacific wave records. Geophys. Res. Lett., 38, L22601, https://doi.org/ 10.1029/2011GL049518.

Gerling, T. W., 1992: Partitioning sequences and arrays of directional ocean wave spectra into component wave systems. J. Atmos. Oceanic Technol., 9, 444-458, https://doi.org/ 10.1175/1520-0426(1992)009<0444:PSAAOD>2.0.CO;2.

Gillett, N. P., T. D. Kell, and P. D. Jones, 2006: Regional climate impacts of the southern annular mode. Geophys. Res. Lett., 33, L23704, https://doi.org/10.1029/2006GL027721.

Gulev, S. K., and L. Hasse, 1998: North Atlantic wind waves and wind stress fields from voluntary observing ship data. J. Phys. Oceanogr., 28, 1107-1130, https://doi.org/10.1175/1520-0485 (1998)028<1107:NAWWAW >2.0.CO;2.

_ and swell in the North Atlantic and North Pacific as revealed by the voluntary observing ship data. J. Climate, 19, 56675685, https://doi.org/10.1175/JCLI3936.1.

Hanson, J. L., and O. M. Phillips, 2001: Automated analysis of ocean surface directional wave spectra. J. Atmos. Oceanic Technol., 18, 277-293, https://doi.org/10.1175/1520-0426(2001) $018<0277$ :AAOOSD $>2.0$. CO; 2 .

Hemer, M. A., J. A. Church, and J. R. Hunter, 2010: Variability and trends in the directional wave climate of the Southern Hemisphere. Int. J. Climatol., 30, 475-491, https://doi.org/10.1002/ joc.1900.

_ Y. Yan, N. Mori, A. Semedo, and X. Wang, 2013: Projected changes in wave climate from a multi-model ensemble. Nat. Climate Change, 3, 471-476, https://doi.org/10.1038/nclimate1791.

Hwang, P. A., F. J. Ocampo-Torres, and H. García-Nava, 2012: Wind sea and swell separation of 1D wave spectrum by a spectrum integration method. J. Atmos. Oceanic Technol., 29, 116-128, https://doi.org/10.1175/JTECH-D-11-00075.1.

Jiang, H., J. E. Stopa, H. Wang, R. Husson, A. Mouche, B. Chapron, and G. Chen, 2016: Tracking the attenuation and nonbreaking dissipation of swells using altimeters. J. Geophys. Res. Oceans, 121, 1446-1458, https://doi.org/ 10.1002/2015JC011536. 
- A. Mouche, H. Wang, A. Babanin, B. Chapron, and G. Chen, 2017a: Limitation of SAR quasi-linear inversion data on swell climate: An example of global crossing swells. Remote Sens., 9, 107, https://doi.org/10.3390/rs9020107.

_- A. V. Babanin, Q. Liu, J. E. Stopa, B. Chapron, and G. Chen, 2017b: Can contemporary satellites really estimate swell dissipation rate? Remote Sens. Environ., 201, 24-33, https://doi.org/10.1016/j.rse.2017.08.037.

Liu, Q., A. V. Babanin, S. Zieger, I. R. Young, and C. Guan, 2016: Wind and wave climate in the Arctic Ocean as observed by altimeters. J. Climate, 29, 7957-7975, https://doi.org/10.1175/ JCLI-D-16-0219.1.

Pérez, J., F. J. Méndez, M. Menéndez, and I. J. Losada, 2014: ESTELA: A method for evaluating the source and travel time of the wave energy reaching a local area. Ocean Dyn., 64, 1181-1191, https://doi.org/10.1007/s10236-014-0740-7.

Portilla, J., 2018: The global signature of ocean wave spectra. Geophys. Res. Lett., 45, 267-276, https://doi.org/10.1002/ 2017GL076431.

— errors for wave data assimilation systems. J. Geophys. Res. Oceans, 121, 209-223, https://doi.org/10.1002/2015JC011309.

—_, F. J. Ocampo-Torres, and J. Monbaliu, 2009: Spectral partitioning and identification of wind sea and swell. J. Atmos. Oceanic Technol., 26, 107-122, https://doi.org/ 10.1175/2008JTECHO609.1.

_ climate and exploitation. Renewable Energy, 57, 594-605, https://doi.org/10.1016/j.renene.2013.02.032.

_ A. L. Caicedo, R. Padilla, and L. Cavaleri, 2015a: Spectral wave conditions in the Colombian Pacific Ocean. Ocean Modell., 92, 149-168, https://doi.org/10.1016/j.ocemod.2015.06.005.

_ L. Lavaleri, and G. P. Van Vledder, 2015b: Wave spectra partitioning and long term statistical distribution. Ocean Modell., 96, 148-160, https://doi.org/10.1016/j.ocemod.2015.06.008.

_ from ocean wave spectra. Geophys. Res. Lett., 43, 1173611743, https://doi.org/10.1002/2016GL071419.

Rueda, A., and Coauthors, 2017: Multiscale climate emulator of multimodal wave spectra: MUSCLE-spectra. J. Geophys. Res. Oceans, 122, 1400-1415, https://doi.org/10.1002/ 2016JC011957.

Semedo, A., K. Sušelj, A. Rutgersson, and A. Sterl, 2011: A global view on the wind sea and swell climate and variability from
ERA-40. J. Climate, 24, 1461-1479, https://doi.org/10.1175/ 2010JCLI3718.1.

- , R. Weisse, A. Behrens, A. Sterl, L. Bengtsson, and H. Günther, 2013: Projection of global wave climate change toward the end of the twenty-first century. J. Climate, 26, 8269-8288, https://doi.org/10.1175/JCLI-D-12-00658.1.

,- R. Vettor, Ø. Breivik, A. Sterl, M. Reistad, C. G. Soares, and D. Lima, 2015: The wind sea and swell waves climate in the Nordic seas. Ocean Dyn., 65, 223-240, https://doi.org/10.1007/ s10236-014-0788-4.

Snodgrass, F. E., K. Hasselmann, G. R. Miller, W. H. Munk, W. H. Powers, and G. E. R. Deacon, 1966: Propagation of ocean swell across the Pacific. Philos. Trans. Roy. Soc. London, 259A, 431-497, https://doi.org/10.1098/rsta.1966.0022.

Stopa, J. E., and K. F. Cheung, 2014: Periodicity and patterns of ocean wind and wave climate. J. Geophys. Res. Oceans, 119 , 5563-5584, https://doi.org/10.1002/2013JC009729.

—, F. Ardhuin, A. V. Babanin, and S. Zieger, 2016: Comparison and validation of physical wave parameterizations in spectral wave models. Ocean Modell., 103, 2-17, https://doi.org/ 10.1016/j.ocemod.2015.09.003.

Thompson, D. W. J., and J. M. Wallace, 1998: The Arctic oscillation signature in the wintertime geopotential height and temperature fields. Geophys. Res. Lett., 25, 1297-1300, https://doi.org/ 10.1029/98GL00950.

Wang, D. W., and P. A. Hwang, 2001: An operational method for separating wind sea and swell from ocean wave spectra. J. Atmos. Oceanic Technol., 18, 2052-2062, https://doi.org/ 10.1175/1520-0426(2001)018<2052:AOMFSW>2.0.CO;2.

Weisse, R., and H. Günther, 2007: Wave climate and long-term changes for the southern North Sea obtained from a highresolution hindcast 1958-2002. Ocean Dyn., 57, 161-172, https://doi.org/10.1007/s10236-006-0094-x.

Young, I. R., 1999: Seasonal variability of the global ocean wind and wave climate. Int. J. Climatol., 19, 931-950, https://doi.org/ 10.1002/(SICI)1097-0088(199907)19:9<931::AID-JOC412> 3.0.CO;2-O.

- S. Zieger, and A. V. Babanin, 2011: Global trends in wind speed and wave height. Science, 332, 451-455, https://doi.org/ 10.1126/science.1197219.

_ J. Jinoth, S. Zieger, and A. V. Babanin, 2012: Investigation of trends in extreme value wave height and wind speed. J. Geophys. Res., 117, C00J06, https://doi.org/10.1029/ 2011JC007753. 